\title{
Temporal contrast sensitivity with peripheral and central stimulation in glaucoma diagnosis
}

\author{
Isabel M Velten, Matthias Korth, Folkert K Horn, Wido M Budde
}

\begin{abstract}
Aims-To evaluate temporal contrast sensitivity with full field, peripheral, and central stimulation and to determine the most sensitive corresponding retinal area for glaucoma damage.

Methods-Temporal contrast sensitivity was determined either with a full field, a peripheral annular area from $30^{\circ}$ to $90^{\circ}$, or a central area from $0^{\circ}$ to $30^{\circ}$ at a frequency of $37.1 \mathrm{~Hz} .232$ eyes of 232 subjects were included. They were classified into four groups: eyes with ocular hypertension (OHT, n = 54), "preperimetric" glaucomas $(n=73)$ with glaucomatous optic disc abnormalities but no visual field loss, "perimetric" glaucomas $(n=53)$ with visual field loss, and 52 normals.

Results-In all four groups, temporal contrast senstitivity was almost equal with full field and peripheral, but significantly higher than with central stimulation (p $<0.001)$. With regard to the diagnostic power of the three different stimulus areas, OHTs and glaucomas were found to be best discriminated from normals by peripheral stimulation.

Conclusions-According to these results, temporal contrast sensitivity seems to be determined by peripheral retinal areas. As the diagnostic power of the three different stimulus areas was best with the peripheral stimulation, this condition should be used for early glaucoma diagnosis.
\end{abstract}

(Br F Ophthalmol 1999;83:199-205)

Glaucoma is one of the most frequent chronic ophthalmological diseases in adults which can lead to irreversible blindness. Early detection and early onset of treatment are the most important factors for preventing progressive glaucoma damage. Thus, one of the major objectives in ophthalmological research in the past has been to find functional and morphological criteria which indicate the start of glaucoma damage in its very early stages before visual field losses occur. Visual field testing is not the most appropriate screening examination for glaucoma. To achieve reliable results, the patient has to be experienced in this examination, and because of its rather long duration, it can be quite distressing for elderly patients. Several morphological studies ${ }^{1-6}$ have evaluated patterns of glaucomatous optic nerve damage which make it possible to diagnose glaucoma in the majority of patients before visual field losses occur. But because of the great variability of optic disc morphology, it is not always quite obvious whether an optic disc demon- strates glaucomatous changes or not, and the observer has to be very experienced. Therefore, there is a need for further functional tests which can additionally be helpful in distinguishing between normal and glaucomatous eyes.

Among these investigations the determination of the temporal contrast sensitivity (TCS) using unpatterned homogeneous but localised stimuli was found to be a sensitive glaucoma test demonstrating losses in patients with ocular hypertension (OHT) or suspected of having glaucoma..$^{7-13}$

We have designed and evaluated a psychophysical test that utilises a full field light stimulus flickering at a frequency of $37.1 \mathrm{~Hz}$. Under these conditions, TCS was found to be significantly reduced not only in glaucoma but also in OHT patients ${ }^{14}{ }^{15}$ and in patients with both increased intraocular pressure (IOP) and glaucomatous optic disc abnormalities but normal visual fields (so called "preperimetric" glaucomas). ${ }^{16}$ At a specificity of $99 \%$ the sensitivities in the preperimetric and perimetric glaucoma groups were $34 \%$ and $59 \%$, respectively. The validity of this test was strengthened by demonstrating significant correlations between contrast threshold on the one hand and visual field defect ${ }^{141517}$ and optic disc ${ }^{15-17}$ or retinal nerve fibre layer damage ${ }^{16}$ on the other. In addition, the results were relatively independent of the opacities of the optic media such as cataract. ${ }^{18}$ Finally, the short duration (5 minutes per eye) and the high reliability of the test $^{1415}$ suggested its use as an additional low cost screening test in glaucoma diagnosis.

Temporal contrast sensitivity is thought to target mainly the functions of the magnocellular retinal ganglion cells ( $\mathrm{M}$ type). ${ }^{19}$ The large retinal ganglion cells are known to be preferably damaged by glaucomatous optic nerve damage. ${ }^{20-22}$

It was the purpose of the present study to test the TCS of a large central $30^{\circ}$ area of the visual field, an area commonly explored by many different strategies for early glaucoma diagnosis, and to compare the results with those obtained from a peripheral annular area beyond $30^{\circ}$ usually neglected in glaucoma diagnosis, and with those obtained with a full field flicker stimulus.

\section{Subjects and methods}

SUBJECTS

Subjects were recruited from our glaucoma service and from the hospital staff. Informed consent was obtained from each individual after an explanation of the nature and possible consequences of the study according to the 
guidelines set by the institutional review board. In all, 232 subjects were tested who satisfied the following criteria: refractive errors less than 9 dioptres (myopic or hyperopic), best refracted visual acuity better than $20 / 30$, no previous cataract surgery, clear optic media, open anterior chamber angle, no systemic illnesses influencing the eye such as diabetes mellitus, vascular, or rheumatic diseases. All participants were at least 23 and not older than 66 years. All subjects underwent a full ophthalmological examination (see below), confirming a normal eye or excluding any ophthalmological diseases other than glaucoma. Only one eye of each individual was included in the study.

CLASSIFICATION OF SUBJECTS

The subjects were classified into four groups: normals, OHTs without any signs of glaucoma damage, "preperimetric" glaucomas, and "perimetric" glaucomas. The "preperimetric" and "perimetric" glaucoma groups included primary and secondary (pigmentary dispersion, pseudoexfoliation) open angle and low tension glaucomas.

Normals

Normals ( $\mathrm{n}=52,23$ females, 29 males, mean age 42 (SD 12.2) years) had no history of IOP above $21 \mathrm{~mm} \mathrm{Hg}$, a normal optic disc, and no visual field losses.

OHTS

Eyes with OHT ( $\mathrm{n}=54,26$ females, 28 males, mean age 44.8 (11.8) years) had a maximum intraocular pressure above $21 \mathrm{~mm} \mathrm{Hg}$, no glaucomatous optic disc abnormalities, and no visual field losses.

\section{"Preperimetric" glaucomas}

Eyes with "preperimetric" glaucomas ( $\mathrm{n}=73$, 30 females, 43 males, mean age 46.5 (11) years) had early glaucomatous optic disc change ${ }^{5}$ and no visual field losses. This group included 62 patients with maximum IOP above $21 \mathrm{~mm} \mathrm{Hg}$ before treatment and 11 patients with "preperimetric" low tension glaucomas (LTG), presenting with a glaucomatous optic disc change only.

\section{"Perimetric" glaucomas}

The glaucoma category (53 eyes, 29 females, 24 males, mean age 51.4 (10.6) years) was defined by glaucomatous changes of the optic disc and glaucomatous visual field losses. This group included 31 patients with a maximum IOP above $21 \mathrm{~mm} \mathrm{Hg}$ and 22 patients with LTG.

If both eyes were normal, one eye was chosen randomly. In glaucoma patients, the eye with the more advanced glaucoma damage was chosen. For both eyes in each subject the following examinations were conducted: best refracted visual acuity, perimetry with a computerised static projection perimeter (Octopus $500 \mathrm{EZ}$, program G1, three phases), slit lamp examination, gonioscopy, applanation tonometry, dilated fundus examination, and 15 degree colour stereophotography of the optic disc.
Visual field indices as described by Flammer et $a l^{23}$ are calculated routinely by the Octopus $500 \mathrm{EZ}$ program G1. Subjects performing in visual field testing with false positive and false negative responses of $>12 \%$ were excluded. Normal visual fields were accepted even if the test was the first one for the subject. Abnormal fields $(\mathrm{MD}>2.8 \mathrm{~dB}$, at least three contiguous test points $5 \mathrm{~dB}$ or more below the age corrected normal threshold) were accepted only if the subject had had at least two examinations with the Octopus 500 G1 perimetry.

The stereophotographies of the optic disc were interpreted and classified by one masked observer as already described. ${ }^{5}{ }^{6}$

\section{THE STIMULUS}

The stimulus of the used full field flicker test has already been described. ${ }^{14-17}$ A modified perimeter bowl was used to present a homogeneous full field diffuse white light stimulus. A sinusoidally flickering white light (frequency $37.1 \mathrm{~Hz}$ ) was transmitted via glass fibre optics into the bowl of $58 \mathrm{~cm}$ in diameter providing a constant mean luminance of $10 \mathrm{~cd} / \mathrm{m}^{2}$. A modulatable $175 \mathrm{~W}$ high pressure xenon arc lamp (Cermax) was used for the illumination of the bowl. The lamp's current provided by an appropriate power supply (PS 150-9, ILC Technology) was controlled by the sine wave of a digital function generator (DF 194, NF Instruments). The full field bowl was located in a darkened, isolated room. The linear and stable range of the light source was tested with a photodiode (SDC). The mean luminance $\left(\mathrm{L}_{\text {mean }}=\left[\mathrm{L}_{\max }+\mathrm{L}_{\text {min }}\right] / 2\right.$, with $\mathrm{L}_{\max }=$ luminance at the peak and $\mathrm{L}_{\min }=$ luminance at the trough of the sinusoid) was calibrated before each measurement with a digital photometer (Tektronix J 16, NITS probe J6503). Its value was adjusted to $10 \mathrm{~cd} / \mathrm{m}^{2}$ in each stimulus area by neutral density filters (Schott) for a pupil diameter of $4.5 \mathrm{~mm}$. For all other pupil diameters the mean luminance was corrected as previously described ${ }^{15}$ so that the retinal illuminance was constant for all eyes. Pupil diameters for the full field condition did not differ significantly between the four study groups (unpaired $t$ test, $\mathrm{p}>0.02$, normals: 3.87 (SD $0.56) \mathrm{mm}$, OHTs $3.67(0.56) \mathrm{mm}$, "preperimetric" glaucomas $3.62(0.57) \mathrm{mm}$, "perimetric" glaucomas $3.81(0.85) \mathrm{mm})$. The temporal contrast is defined as $\mathrm{C}=\left(\mathrm{L}_{\text {max }}-\mathrm{L}_{\text {min }}\right) /\left(\mathrm{L}_{\text {max }}+\right.$ $\left.\mathrm{L}_{\min }\right) \times 100 \%$. With our light source, it could be varied from $0 \%$ to $58 \%$.

The stimulus dimensions used were either the full field of $58 \mathrm{~cm}$ in diameter, a peripheral stimulus area from $30^{\circ}$ to $90^{\circ}$, or a central area from $0^{\circ}$ to $30^{\circ}$. Those areas not used for stimulation were screened by black cardboard except for that part of the bowl above the subject's head where the light guide entered the perimeter. Thus, for central stimulation the $30^{\circ}$ to $90^{\circ}$ periphery was screened from illumination, while for peripheral stimulaton a black $60^{\circ}$ diameter disc covered the central area of the bowl (see Fig 1). In all three test conditions, the mean luminance of the stimulus areas was adjusted to the value determined before (see later). In order to check for possible 
Full field

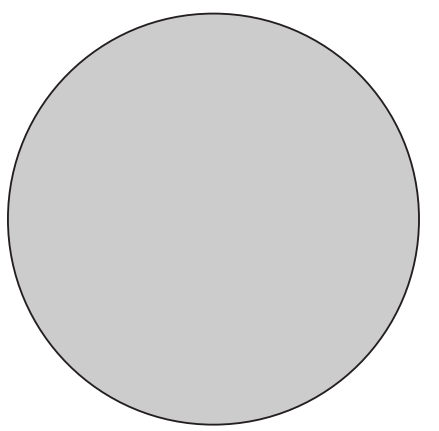

Peripheral

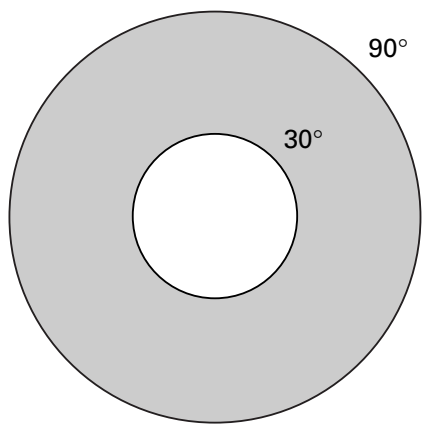

Central stimulation

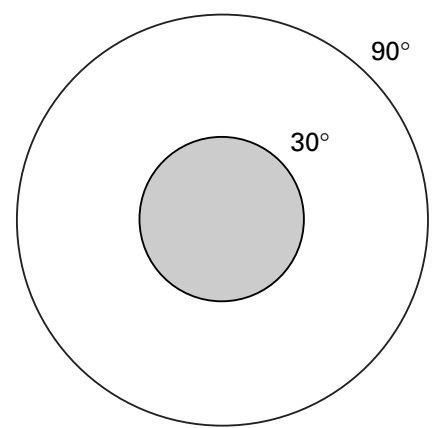

Figure 1 A full field bowl (58 cm in diameter) was used to produce a homogeneous white flickering light. The areas to be tested were either the full field, a peripheral annular area from $30^{\circ}$ to $90^{\circ}$, or a central area from $0^{\circ}$ to $30^{\circ}$. Those areas not used for stimulation were screened by black cardboard.

different pupil sizes for the three different stimulus conditions pupil diameters were determined in a group of 16 normals. No significant differences were found between conditions (unpaired $t$ test, $\mathrm{p}>0.02$ ). Thus, one may assume that all tests were carried out with comparable levels of retinal illumination under all conditions and in all subjects.

\section{PROCEDURE}

Without dark adaptation the participant was brought into the dark room and seated at the perimeter. No correcting lenses were used. For full field examination people were asked to look straight ahead into the perimeter. For testing the peripheral or the central areas the subject was instructed to fix one black (for the central stimulus) or white (for the peripheral stimulus) point in the centre of the bowl. The order of the three test conditions was chosen randomly for each subject. At the time of testing, all eyes had pupil diameters between 2 and $6 \mathrm{~mm}$. The contrast of the whole field flickering stimulus was increased progressively in fixed steps of $0.1 \%$ until it was detected by the subject. Before testing the contrast threshold, a preview of the stimulus was given to each subject, and the test procedure was carefully explained. After one response, the flicker contrast was reduced to $0 \%$ for 5 seconds, and the threshold was tested twice more. Then the initial contrast was set about $25 \%$ above the contrast threshold found in the three previous tests. The flicker contrast was reduced in fixed steps of $0.1 \%$ until the subject noticed the flicker stimulus disappear. The six single values of the temporal contrast threshold were averaged and corrected according to Stiles Crawford effect for different pupil diameters as already described. ${ }^{15-17}$ The reciprocal of the resulting value is the temporal contrast sensitivity. Its log value was used for further evaluation.

In the normal eyes, log temporal contrast sensitivity decreased significantly $(\mathrm{p}<0.01)$ with age (23-66 years). The OHT and "preperimetric" glaucoma group did not differ significantly from normals in mean age ( $p$ $>0.01$ ), but there was a significant difference in the "perimetric" glaucoma group. Thus, before statistical analysis, the values of the temporal contrast sensitivities of all participants in the three different stimulus areas were age normalised by dividing each individual value by the equation of the linear regression of temporal contrast sensitivity to age and multiplying by the mean. For these calculations, the results of the 52 normals in the corresponding stimulus area were used as reference.

\section{STATISTICAL ANALYSIS}

Analysis among related samples was made using the Wilcoxon's signed paired rank test and paired $t$ test. Comparisons between groups regarding the diagnostic power of the three different flicker stimuli used the unpaired $t$ test. Sensitivities and specificities were calculated to describe the diagnostic value of the three different test conditions. Sensitivity was defined as the proportion of positive test results in the OHT and the two glaucoma groups and specificity as the proportion of negative test results among the controls. To judge the percentage of correctly classified patients, the sensitivities in patient groups were calculated for a fixed specificity of $96 \%$.

\section{Results}

The log temporal contrast sensitivities in the four groups with each of the three different stimulus areas are presented as box plots in Figure 2. In all four study groups, temporal contrast sensitivity was significantly $(p<0.001)$ higher with full field and peripheral compared with central stimulation. There was only a little difference between full field and peripheral stimulation in all study groups. It was not significant $(p>0.01)$ in the normals, the OHTs, or the "perimetric" glaucomas, but in "preperimetric" glaucoma group it was ( $p$ $<0.01$ ). Table 1 shows the number of subjects obtained from a rank test and the results of the paired $t$ test comparing the temporal contrast sensitivity between the three different stimulus areas.

The diagnostic power of the three tests is evaluated by the receiver operating characterisitic (ROC) curves in Figure 3 for "perimetric" glaucoma patients. Although there is only little difference between the three curves, a tendency towards best sensitivities with peripheral stimulation can be observed for high specificities between $90 \%$ and $100 \%$. The next sensitive test condition is the full field stimulus; 


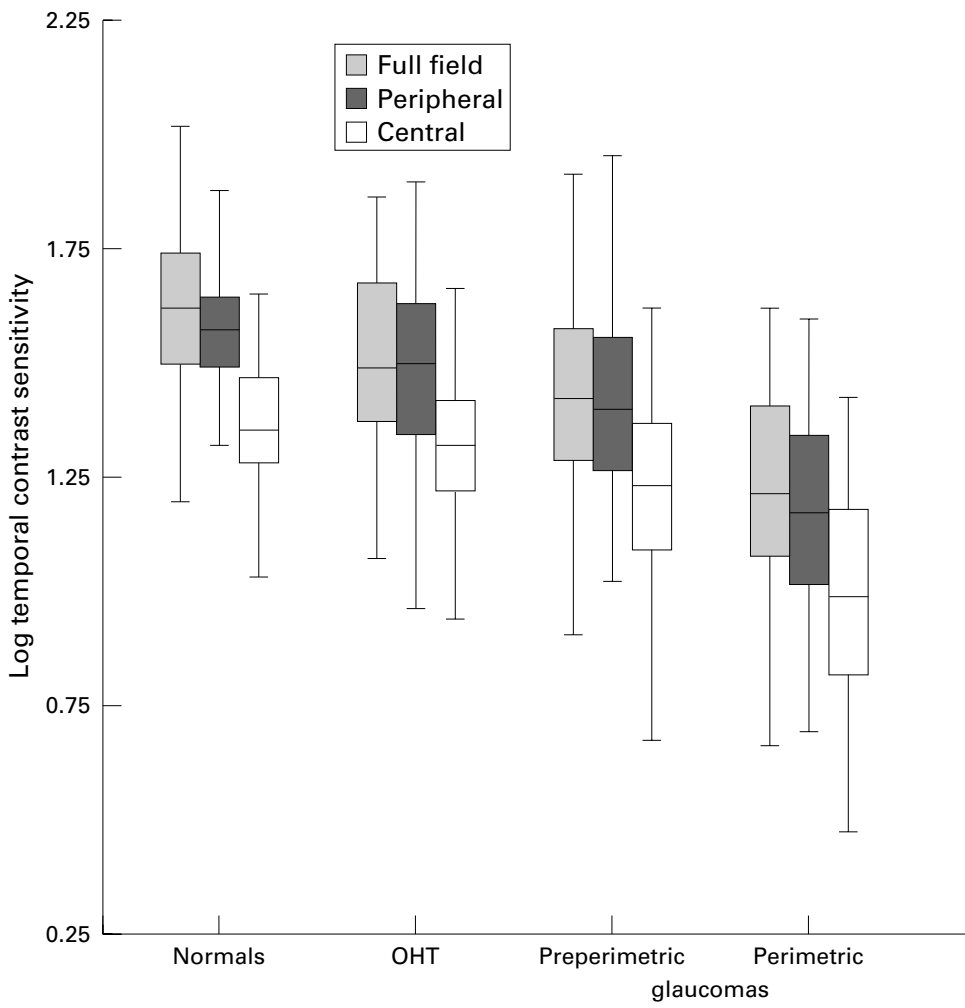

Figure 2 Box plots of temporal contrast sensitivity values determined with three different stimuli (full field, peripheral, and central flicker test) in four different subjects groups (OHT $=$ ocular hypertensives). The temporal contrast sensitivity was almost equal with full field and peripheral, but significantly higher $(p<0.001)$ than with central stimulation. The boxes include $50 \%$ of measured values (25\% and $75 \%$ percentiles) and show the position of the median (horizontal line). Error bars indicate the 1.5-fold of the interquartile distance from the upper and lower box edges. The position of the medians (solid lines within the boxes) illustrates the markedly lower temporal contrast sensitivity with central compared with full field and peripheral stimulation. Additionally, it shows the decreasing temporal contrast sensitivity with increasing stage of glaucoma with all three stimulus areas.

Table 1 Comparison of temporal contrast sensitivity between full field, peripheral, and central stimulation

\begin{tabular}{|c|c|c|c|c|c|}
\hline $\begin{array}{l}\text { TCS compared } \\
\text { between } \\
\text { different } \\
\text { stimulated } \\
\text { areas }\end{array}$ & $\begin{array}{l}\text { Number of subjects of a } \\
\text { rank test and results of } \\
\text { the paired t test }\end{array}$ & Normals & $\begin{array}{l}\text { Ocular } \\
\text { hypertensives }\end{array}$ & $\begin{array}{l}\text { Preperimetric } \\
\text { glaucomas }\end{array}$ & $\begin{array}{l}\text { Perimetric } \\
\text { glaucomas }\end{array}$ \\
\hline \multirow{3}{*}{$\begin{array}{l}\text { Central } v \\
\text { peripheral }\end{array}$} & central > peripheral & 0 & 2 & 3 & 5 \\
\hline & peripheral > central & 52 & 52 & 70 & 48 \\
\hline & $t$ value $(\mathrm{p})$ & $15.16^{\star \star}$ & $10.5^{\star \star}$ & $13.34^{\star \star}$ & $9.36^{\star \star}$ \\
\hline \multirow{3}{*}{$\begin{array}{l}\text { Central } v \text { full } \\
\text { field }\end{array}$} & central > full field & 0 & 1 & 1 & 3 \\
\hline & full field > central & 52 & 53 & 72 & 50 \\
\hline & $t$ value $(\mathrm{p})$ & $15.82^{\star \star}$ & $12.16^{\star \star}$ & $14.19^{\star \star}$ & $11.53^{\star \star}$ \\
\hline \multirow{3}{*}{$\begin{array}{l}\text { Peripheral } v \\
\text { full field }\end{array}$} & peripheral > full field & 18 & 24 & 29 & 18 \\
\hline & full field $>$ peripheral & 34 & 30 & 44 & 35 \\
\hline & $t$ value $(\mathrm{p})$ & $2.41(\mathrm{~ns})$ & 1.8 (ns) & $3.01^{\star}$ & $2.36(\mathrm{~ns})$ \\
\hline
\end{tabular}

$\mathrm{ns}=$ not significant; ${ }^{\star} \mathrm{p}<0.01 ;{ }^{\star \star} \mathrm{p}<0.001$

Table 2 Diagnostic power of the flicker test with the three different stimulus areas for the three patient groups

\begin{tabular}{lllll}
\hline & $\begin{array}{l}\text { Sensitivities at a } \\
\text { prefixed specificity } \\
\text { of 96\% and result } \\
\text { of the unpaired t test }\end{array}$ & $\begin{array}{l}\text { Ocular } \\
\text { hypertensives }\end{array}$ & $\begin{array}{l}\text { "Preperimetric" } \\
\text { glaucomas }\end{array}$ & $\begin{array}{l}\text { "Perimetric" } \\
\text { glaucomas }\end{array}$ \\
\hline Central stimulation & sensitivity (\%) & 11.1 & 20 & 51 \\
Peripheral stimulation & p value & $\mathrm{ns}$ & $\star \star$ & $\star \star$ \\
Full field stimulation & sensitivity (\%) & 24.1 & 37 & 73.6 \\
& p value & $\star$ & $\star \star$ & $\star \star$ \\
& sensitivity (\%) & 20.4 & 32.9 & 66.2 \\
& p value & $\star$ & $\star \star$ & $\star \star$
\end{tabular}

ns $=$ not significant; ${ }^{\star} \mathrm{p}<0.01 ;{ }^{\star \star} \mathrm{p}<0.001$.

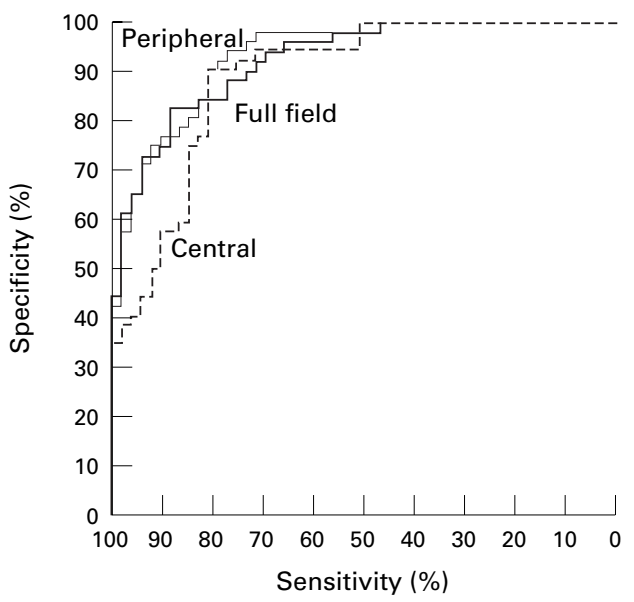

Figure 3 Receiver operating characteristic (ROC) curves for determination of temporal contrast sensitivity in

"perimetric" glaucomas with three different stimulus areas (full field, peripheral, and central stimulation). Although there is only little difference between the three stimulus areas, for specificities $>90 \%$ peripheral stimulation offers highest sensitivities. The next sensitive test condition is the full field stimulus, followed by the central stimulus which is least sensitive.

however, its ROC curve partially overlaps with that of the peripheral stimulus. The central stimulus is least sensitive. Table 2 shows the sensitivities for the patient groups at a prefixed specificity of $96 \%$ and the $\mathrm{p}$ values of the unpaired $t$ test. A specificity of $96 \%$ was chosen, as it includes two standard deviations from the mean value. Ocular hypertensive eyes were significantly $(\mathrm{p}<0.01)$ discriminated from normals by peripheral and full field stimulation, but did not differ significantly with central stimulation. "Preperimetric" and "perimetric" glaucomas differed significantly ( $p$ $<0.001$ ) with all three stimulus areas, but sensitivity was highest with peripheral stimulation.

\section{Discussion}

The high diagnostic power of the TCS test under the full field condition (Fig 3, Table 2) confirms our earlier results obtained with this stimulus. One important new finding in the present study, however, is that with the peripheral stimulation beyond $30^{\circ}$ eccentricity, contrast sensitivity was not significantly different from full field stimulation in most patient groups (Fig 2, Table 1). This may suggest that even in the full field condition subjects' responses were initiated from peripheral retinal areas. In fact, many subjects occasionally reported that with the full field stimulus flicker was noticed first in the far periphery of the visual field.

The most important result of our present study, however, is the rather unorthodox observation of a higher diagnostic sensitivity for glaucoma detection for the peripheral $30^{\circ}$ to $90^{\circ}$ eccentricity stimulation (Fig 3, Table 2). This suggests that in glaucoma diagnosis attention should also be paid to those peripheral retinal areas lying outside the conventionally tested central $30^{\circ}$.

A comparison of TCS between different locations within the visual field has been made in a few previous studies using flickering light 
spots. Thus, Tyler ${ }^{92}$ found in normals with flickering targets of various sizes an increasing sensitivity and, consequently, increasing flicker fusion frequency (FFF) with increasing peripheral location (up to $45^{\circ}$ ) when high frequencies above $20 \mathrm{~Hz}$ were used. In OHT and even more pronounced in glaucoma patients, a higher proportion of significant losses occurred at $20^{\circ}$ than in the centre of the visual field. In addition, a preponderance of high frequency losses (above $25 \mathrm{~Hz}$ ) was noted with the more peripheral position while low frequency losses (below $25 \mathrm{~Hz}$ ) were more common with foveal stimulation. ${ }^{9}$ A similar trend was observed by Stamper ${ }^{10}$ and Tytla et al. ${ }^{11}$

Subsequent detailed investigations showed that TCS and FFF strongly depended on the size, retinal location, and luminance of the stimulus. Thus, it became clear that the use of a small stimulus requires that for a proper interpretation of the results the anatomical and physiological inhomogeneities of the different retinal eccentricities are taken into account. A correction of the stimulus size at different retinal locations according to the cortical magnification factor showed that with increasing eccentricity the FFF increased in direct proportion with the cone outer segment diameter, while TCS increased in proportion with cone outer segment length. ${ }^{24}$ When the stimulus size was adjusted to excite equal numbers of cones at each retinal location (up to $55^{\circ}$ ), the FFF varied with the meridian at a constant eccentricity and increased with eccentricity along all meridians leading to contour maps of FFF across visual field. ${ }^{25}$ These variations in FFF could be explained by independent variations of both the sensitivity and the temporal dynamics at different retinal locations. Finally, when stimulus field size was adjusted to stimulate equal numbers of retinal ganglion cells and its luminance was adjusted to equate the luminous flux collected by the different retinal ganglion cell receptive fields, ${ }^{26}$ the modulation sensitivity remained constant at all eccentricities (up to $70^{\circ}$ ) and flicker rates tested. In glaucoma research it is not known whether, for testing flicker responses in a certain retinal area, a careful control of the variables discussed above is necessary in order to obtain an optimal discrimination between normals and patients. The stimuli used by current methods of flicker perimetry neglect the peculiarities of different retinal areas and their consideration would require much technical examination and a great deal of cooperation from the patient, making such a test impractical for screening purposes. The full field flicker test used in the present study likewise neglects, for the sake of simplicity, the demands of different retinal points for different stimulus adjustments in order to function equally well. But our test requires no fixation-it is quick, reliable, and sensitive. Even with the present stimulus modifications utilising central and peripheral stimulation accurate fixation seems uncritical in view of the rather large stimulus areas used and the test loses only little of its simplicity.
The best known psychophysical test exploring the very far periphery in glaucoma diagnosis is the conventional kinetic Goldmann perimetry which uses light spots that are moved along various meridians from the outer edges of the visual field towards its centre. However, modern sensory tests for early glaucomatous losses usually probe the central $30^{\circ}$ of the visual field. This is true especially for static projection perimetry, like the Tübingen perimeter, which has shown that the early stages 1 and 2 of perimetric defects are detected in the Bjerrum area. ${ }^{27}$ Only with advanced defects (stage 3 ) the central damage shows a nasal break through into the periphery. Other programs typically used for early glaucoma diagnosis in automated computer controlled static projection perimeters nowadays available also concentrate on the central $30^{\circ}$ of the visual field-for example, the Octopus program $\mathrm{G} 1^{28}{ }^{29}$ and the Humphrey visual field analyser 24-2 and 30-2 programs used for both white on white and blue on yellow perimetry. $^{30}{ }^{31}$ Further examples for central visual field tests are the less frequently applied techniques of high pass resolution perimetry, ${ }^{32}$ white noise scotometry, ${ }^{33}$ colour perimetry, ${ }^{34}$ colour contrast perimetry, ${ }^{35}$ flicker perimetry, ${ }^{36}{ }^{37}$ frequency doubling perimetry, ${ }^{38}$ and motion perimetry. ${ }^{39-41}$

Likewise, psychophysical tests other than perimetric ones are commonly applied also within the central $30^{\circ}$ of visual field. A typical example is the determination of the spatial contrast sensitivity. ${ }^{42}$ Early glaucoma diagnosis seems to benefit from the use of flickering patterns (spatiotemporal contrast sensitivity tests) especially with test locations slightly eccentric between $7.5^{\circ}$ and $25^{\circ}$ where early visual field defects are expected first. ${ }^{173-46}$ Tests for motion vision in glaucomas have applied visual displays of various sizes and eccentric locations; however, in none of these tests was the stimulus presented in a visual area beyond $30^{\circ}$ eccentricity. ${ }^{47-53}$ Similar spatial limitations were used for stimuli testing the brightness sense, ${ }^{54-56}$ the grating resolution acuity, ${ }^{57}$ and the vernier threshold. ${ }^{58}$ Colour vision tests which look mainly for deficits in blue colour vision are usually carried out under central fixation and never involve the far retinal periphery.

There are two further psychophysical tests described in the literature for glaucoma diagnosis that utilise full field stimulation. One is the so called whole field scotopic retinal sensitivity test presenting ganzfeld light stimuli at a slow rate of $0.5 \mathrm{~Hz}$ on a zero background and as incremental stimuli on different background luminances..$^{59}$ For this test, the patient has to dark adapt for 30 minutes. In the other test ${ }^{60}$ a $25 \mathrm{~Hz}$ flickering light was presented as an incremental stimulus on a fixed background. Both tests allowed a good separation of patients from normals. In the present study a different stimulus paradigm was used and the results suggest that the response to the full field stimulus is initiated from the far periphery beyond $30^{\circ}$. It is not known whether this is also 
probable for the other two ganzfeld stimuli mentioned above.

In summary, the present study suggests that in glaucoma diagnosis peripheral retinal areas outside the commonly tested $30^{\circ}$ regions of the visual field should not be neglected. The TCS in these peripheral areas is significantly higher in all subject groups than in the central $30^{\circ}$ area (Fig 2, Table 1) and it is rather similar to the full field results. The diagnostic power with the far peripheral stimulation is higher than with central stimulation (Fig 3, Table 2). For high specificities above $90 \%$ the peripheral stimulation is even more sensitive than the full field stimulation. This is true not only for the advanced glaucomas but also for patients with optic disc damage but without perimetric defects and even for the OHT patients. Thus, the peripheral TCS test should be preferred.

Supported by Deutsche Forschungsgemeinschaft "Sonderforschungsbereich Glaukome" (SFB 539).

No proprietary interests.

The authors thank Professor Dr Jonas and Dr Gründler for the classification of all stereophotographies of the optic disc. The authors also thank Sonja Prenzel for technical assistance in performing the flicker test.

1 Tuulonen A, Airaksinen PJ. Initial glaucomatous optic disk and retinal nerve fiber layer abnormalities and their progression. Am f Ophthalmol 1991;111:485-90.

2 Caprioli J. Discrimination between normal and glaucomatous eyes. Invest Ophthalmol Vis Sci 1992;33:153-9.

3 Quigley HA, Katz J, Derick RJ, et al. An evaluation of optic disc and nerve fiber layer examinations in monitoring progression of early glaucoma damage. Ophthalmology 1992; 99:19-28.

4 Airaksinen PJ, Tuulonen A, Alanko HI. Rate and pattern of neuroretinal rim area decrease in ocular hypertension and glaucoma. Arch Ophthalmol 1992;110:206-10.

5 Jonas JB, Fernandez M, Stürmer J. Pattern of glaucomatous neuroretinal rim loss. Ophthalmology 1993;99:6-7.

6 Jonas JB, Königsreuther KA. Optic disc appearance in ocular hypertensive eyes. Am f Ophthalmol 1994;117:732-40.

7 Atkin A, Bodis-Wollner I, Wolkstein M, et al. Abnormalities of central contrast sensitivity in glaucoma. Am F Ophthalmol 1979;88:205-11

8 Atkin A, Bodis-Wollner I, Podos S, et al. Flicker threshold and VEP lantency in ocular hypertension and glaucoma Invest Ophthalmol Vis Sci 1983;24:1524-8.

9 Tyler C. Specific deficits of flicker sensitivity in glaucoma and ocular hypertension. Invest Ophthalmol Vis $\mathrm{Sci}$ 1981;20:204-12.

10 Stamper RL. The effect of glaucoma on central visual function. Trans Am Ophth Soc 1984;82:792-825.

11 Tytla ME, Trope GE, Bunciec R. Flicker sensitivity in treated ocular hypertension. Ophthalmology 1990;97:3643.

12 Holopigian K, Seiple W, Mayron C, et al. Electrophysiologi$\mathrm{cal}$ and psychophysical flicker sensitivity in patients with primary open-angle glaucoma and ocular hypertension. Invest Ophthalmol Vis Sci 1990;31:1863-8.

13 Breton ME, Wilson TW, Wilson R, et al. Temporal contras sensitivity loss in primary open-angle glaucoma and glaucoma suspects. Invest Ophthalmol Vis Sci 1991;32 2931-41.

14 Korth M, Horn F, Martus P. Einfacher zeitlicher Kontrastempfindlichkeits-Test in der GlaukomDiagnostik. Klin Montsbl Augenheilkd 1993;203:99-103.

15 Horn FK, Korth M, Martus P. Quick full-field flicker test in glaucoma diagnosis: correlations with perimetry and papillometry. $\mathcal{F}$ Glaucoma 1994;3:206-13.

16 Horn JK, Jonas JB, Korth M, et al. The full-field flicker test in early diagnosis of chronic open-angle glaucoma. $A m \mathcal{F}$ in early diagnosis of chronic

17 Horn F, Martus P, Korth M. Comparison of temporal and spatiotemporal contrast-sensitivity tests in normal subjects and glaucoma patients. Ger $\mathcal{F}$ Ophthalmol 1995;4:97-102.

18 Jünemann A, Horn F, Budde WM, et al. The full-field temporal contrast sensitivity test for glaucoma: influence of cataract. ARV

19 Kaplan E, Lee BB, Shapley RM. New views of primate retinal function. In: Osborne NN, Chader GJ, eds. Progress in retinal research. Elmsford, NY: Pergamon Press, 1990;9: 273-335.

20 Quigley HA, Sanchez RM, Dunkelberger GR, et al. Chronic glaucoma selectively damages large optic nerve fibers. Invest Ophthalmol Vis Sci 1987; 28:913-20.

21 Quigley HA, Dunkelberger GR, Grenn WR. Chronic human glaucoma causing selectively greater loss of large optic nerve fibers. Ophthalmology 1988;95:357-63.
22 Glovinsky Y, Quigley HA, Dunkelberger GR. Retinal anglion cell loss is size dependent in experimental ganglion cell loss is size dependent in experimen

23 Flammer J, Drance SM, Augustiny L, et al. Quantification of glaucomatous visual field defects with automated perimetry. Invest Ophthalmol Vis Sci 1985;26:176-81.

24 Tyler CW. Analysis of visual modulation sensitivity. II. Peripheral retina and the role of photoreceptor dimensions. 7 Opt Soc Am A 1985;2:393-8.

25 Tyler CW. Analysis of visual modulation sensitivity. III. Meridional variations in peripheral flicker sensitivity. $\mathcal{F} O p t$ Soc Am A 1987;4:1612-19.

26 Raninen A, Rovamo J. Retinal ganglion-cell density and receptive-field size as determinants of photopic flicker sensitivity across the human visual field. F Opt Soc Am A 1987; 4:1620-6.

27 Aulhorn E, Karmeyer H. Frequency distribution in early glaucomatous visual field defects. Doc Ophthalmol Proc Series 1976;14:75-83.

28 Zulauf $M$. Normal visual fields measured with Octopus program G1. I. Differential light sensitivity at individual test locations. Graefes Arch Clin Exp Ophthalmol 1994;232:50915.

29 Zulauf M, LeBlanc RP, Flammer J. Normal visual fields measured with Octopus-program G1. II. Global visual field indices. Graefes Arch Clin Exp Ophthalmol 1994;232:51622 .

30 Sample PA, Taylor JDN, Martinez GA, et al. Shortwavelength color visual fields in glaucoma suspects at risk. Am f Ophthalmol 1993;115:225-33.

31 Johnson CA, Adams AJ, Casson EJ, et al. Blue-on-yellow perimetry can predict the development of glaucomatous visual field loss. Arch Ophthalmol 1993;11:645-50.

32 Frisen L. High-pass resolution perimetry. Doc Ophthalmol 1993;83:1-25.

33 Aulhorn E, Köst G. Rauschfeldkampimetrie. Eine neuartige perimetrische Untersuchungs-weise. Klin Monatsbl Augenheilkd 1988;192:284-8.

34 Hart WM, Gordon MO. Color perimetry of glaucomatous visual field defects. Ophthalmology 1984;91:338-46.

35 Hart WM, Burde RM. Color contrast perimetry. The spatial distribution of color defects in optic nerve and retinal diseases. Ophthalmology 1985;92:768-76.

36 Lachenmayr B, Gleissner M, Rothbächer H. Automatisierte Flimmerperimetrie. Fortschr Ophthalmol 1989;86:695-701.

37 Austin MW, O'Brien CJ, Wishart PK. Flicker perimetry using a luminance threshold stategy at frequencies from $5-25 \mathrm{~Hz}$ in glaucoma, ocular hypertension and normal controls. Curr Eye Res 1994;13:717-23.

38 Johnson CA, Samuels SJ. Screening for glaucomatous visual field loss with freuquency-doubling perimetry. Invest Ophthalmol Vis Sci 1997;38:413-14.

39 Wall M, Jennisch CS, Munden PM. Motion perimetry identifies nerve fiber bundle-like defects in ocular hypertension. Arch Ophthalmol 1997;115:26-33.

40 Joffe KM, Raymond JE, Chrichton A. Motion coherence perimetry in glaucoma and suspected glaucoma. Vis Res 1997;37:955-64.

41 Bosworth CF, Sample PA, Weinreb RN. Perimetric motion thesholds are elevated in glaucoma suspects and glaucoma patients. Vis Res 1997;37:1989-97.

42 Arden GB, Jacobson JJ. A simple grating test for contrast sensitivity: preliminary results indicate value in screening for glaucoma. Invest Ophthalmol Vis Sci 1978;17:23-32.

43 Lundh BL. Central and peripheral contrast sensitivity for static and dynamic sinusoidal gratings in glaucoma. Acta Ophthalmol 1985;63:487-92.

44 Korth M, Horn F, Storck B, et al. Spatial and spatiotemporal contrast sensitivity of normal and glaucoma eyes. Graefes Arch Clin Exp Ophthalmol 1989;227:428-35.

45 Falcao-Reis F, O'Donaghue E, Buceti R, et al. Peripheral contrast sensitivity in glaucoma and ocular hypertension. Br f Ophthalmol 1990;74:712-16.

46 Lundh BL, Gottval E. Peripheral contrast sensitivity for dynamic sinusoidal gratings in early glaucoma. Acta Ophthalmol Scand 1995;73:202-6.

47 Fitzke FW, Poinoosawmy D, Ernst W, et al. Peripheral displacement thresholds in normals, ocular hypertensives and glaucoma. In: Greve EL, Heill A, eds. 7th International visual field symposium. Dordrecht: Martinus Nijhof/Junk, 1987:447-52.

48 Silverman SE, Trick GL, Hart WM. Motion perception is abnormal in primary open-angle glaucoma and ocular hypertension. Invest Ophthalmol Vis Sci 1990;31:722-9.

49 Bullimore MA, Wood JM, Swenson K. Motion perception in glaucoma. Invest Ophthalmol Vis Sci 1993;34:3526-33.

50 Ruben S, Fitzke F. Correlation of peripheral displacement hresholds and optic disc parameters in ocular hypertension. Br f Ophthalmol 1994;78:291-4

51 Baez KA, McNaught AI, Dowler JGF, et al. Motion detection threshold and field progression in normal tension glaucoma. Br f Ophthalmol 1995; 79:125-8.

52 Trick GL, Steinman SB, Amyot M. Motion perception deficits in glaucomatous optic neuropathy. Vis Res 1995;35: 2225-33.

53 Scholl HPN, Zrenner E. Motion thresholds of coloured stimuli of different luminance contrasts are increased in ocular hypertension and early prrimary open-angle glaucoma (POAG). In: Drum B, ed. Colour vision deficiencies XII. Dordrecht: Kluwer, 1995:73-85.

54 Teoh SL, Allan D, Dutton GN, et al. Brightness discrimination and contrast sensitivity in chronic glaucoma-a clinical study. Br f Ophthalmol 1990;74:215-19. 
55 Borgmann C, Steiner H, Dutton GN. Optimum technique of light brightness assessment in control subjects and patients with ocular hypertension and glaucoma. Ophthal mologica 1991;203:126-32.

56 Cummins D, MacMillan ES, Heron G, et al. Simultaneous interocular brightness sense testing in ocular hypertension and glaucoma. Arch Ophthalmol 1994;112:1198-203.

57 Anderson RS, O'Brien C. Psychophysical evidence for a selective loss of $\mathrm{M}$ ganglion cells in glaucoma. Vis Res 1997;37:1079-83.
58 Piltz JR, Swindale NV, Drance SM. Vernier thresholds and alignment bias in control, suspect, and glaucomatous eyes.

59 Glovinsky Y, Quigley HA, Drum B, et al. A whole-field scotopic retinal sensitivity test for the detection of early glaucoma damage. Arch Ophthalmol 1992;110: 486-90.

60 Feghali JG, Bocquet X, Charlier J, et al. Static flicker perimetry in glaucoma and ocular hypertension. Curr Eye Res 1991;10:205-11. 